\title{
A Novel Real-Time Online Payment Platform for E-commerce Website Running on Local Machine
}

\author{
Odey Adinya John, Okwori Okpe Anthony, Siman Emmanuel
}

Department of Computer Science, Federal University Wukari, Wukari, Nigeria

Email address:

johnodey@fuwukari.edu.ng (O. A. John), okwori@fuwukari.edu.ng (O. O. Anthony), siman.emmanuel@yahoo.com (S. Emmanuel)

To cite this article:

Odey Adinya John, Okwori Okpe Anthony. A Novel Real-Time Online Payment Platform for E-commerce Website Running on Local Machine. International Journal of Information and Communication Sciences. Vol. 4, No. 1, 2019, pp. 1-6. doi: 10.11648/j.ijics.20190401.11

Received: March 16, 2017; Accepted: May 15, 2017; Published: May 15, 2019

\begin{abstract}
This paper outlines a novel approach to the integration of a real time payment platform on an ecommerce website hosted locally. A local ecommerce website; Publication Marketing System (PMS) was developed to enable sales and marketing of electronic publications. It was integrated with an easy- to- use payment platform; Voguepay using tightly coupled PhP codes. NGrok was incorporated to achieve a localhost to real time tunneling through the internet to the online payment Platform. This provides an easy and less expensive way of achieving a real-time online payment for e-commerce website and all other websites involving online payments running on local machines in Nigeria.
\end{abstract}

Keywords: E-commerce, Ngrok, Online-Payment, Real-Time, Tunneling, Voguepay

\section{Introduction}

One of the greatest advancements made in information technology is the introduction of online marketing. An online market is a virtual market on the internet where customers can browse a catalogue and select products of interest for ordering [1]. With the rapid growth of Information and Communication Technology (ICT), online marketing (e-commerce) is now acting as a means of carrying out business transactions through electronic means such as internet connections. E-commerce is the most recent step in the evolution of business transactions as it replaces or augments the swapping of money or goods with the exchange of information from computer to computer (Slater, 2000) in [2].

Every e-commerce website uses electronic payment system which is a paperless monetary transaction. The telecommunications revolution from 2001 and banking consolidation of 2005-2006 have provided a strong foundation for growth of electronic payments [3]. Electronic payment (E-payment) is a subset of an e-commerce transaction to include electronic payment for buying and selling of goods and services offered through the Internet. With the advent of computers and electronic communications, a large number of alternative electronic payment systems have emerged. These include debit cards, credit cards, electronic funds transfers, direct credits, direct debits, internet banking and e-commerce payment systems [17]. As technology develops, the range of devices and processes to transact electronically continues to increase while the percentage of cash and cheque transactions continue to decrease [2]. In the Nigerian context, e-payment is effecting payments from one end to another through the medium of the computer without manual intervention beyond inputting the payment data. The e-payment system is an operational network governed by laws, rules and standards that links bank accounts and provides the functionality of monetary exchange using bank deposits. It is the infrastructure consisting of institutions, instruments, rules, procedures, standards and technical means established to effect the transfer of monetary value between parties discharging mutual obligations [4].

This mode of payment reduces paper work by eliminating manual receipt for a purchased item. It equally reduces transaction cost by eliminating transportation of customers to the shop before making payment. It is user friendly and less time consuming than manual payment as customers can pay for products from the comfort of their home [5]. The electronic payment equally enables customers to purchase items from e-commerce website regardless of distance barrier 
hence expanding the merchant's market reach. It also has the ability to track individual spending; to facilitate the design of products by banks. It equally reduces cash handling and printing costs. Electronic Payment Systems (EPS) apart from its conveniences and safety also have other significant number of economic benefits which include mobilising savings and ensuring most of the cash available in the country are with banks.

Over the years, most students and other researchers in ecommerce website demonstrates their works on local machine through simulations due to high cost of subscribing to a payment processor, difficulties in incorporating a subscribed payment processor into an application and the high cost of hosting a website. This paper aims at demonstrating the integration and implementation of a payment processor (Voguepay) as well as an easy and cheap method of tunneling a web application running on local machine to the Internet using ngrok technology.

A Voguepay payment processor is a Nigerian online payment platform that allows customers to accept payment on their e-commerce websites. This processor has efficient security system, very easy to integrate and verify and is equally less expensive. One of the Voguepay's uniqueness is that, it gives room for customers to accept payment on their websites by supporting automatic withdrawal to the merchant's bank account unlike other payment processors where merchants manually make withdrawal request [6]. This processor can process local and international Visa, Master and Verve cards. It equally accepts recurrent billing which simplifies the payment process for both the customer and the merchant as the constant payment is automatically debited from the card at pre-defined time frame. The processor enables Merchants to display the paying currency for the customer at payment page. Voguepay's comprehensive integrated solutions and services are quite understandable. VoguePay also distinguishes itself from other online payment processors with its array of features guided by its core values: Security and Reliability [7]. This payment processor has multiple security tools such as SSL, IP monitoring, encryption, User ban and suspension management, risk evaluation management system, email and phone number verification as well as one-time-password (OTP) system. All this features helps to minimize fraud by monitoring fraudulent IP addresses, securing the payment page, user authentication and host of others.

The publication marketing system (PMS) developed accesses the pay page of voguepay payment processor using ngrok technology. Ngrok is a tunneling, reverse proxy that establishes secure tunnels from a public endpoint to a locally running network service while capturing all traffic for inspection and replay [8]. It is a technology that enables website developer forward their web application running on local machine to the Internet [9].

\section{Methodology}

A local e-commerce website; Publication Marketing System (PMS) was developed to enable sales and marketing of electronic publications. It was integrated with an easy-touse payment platform; Voguepay using tightly coupled $\mathrm{PhP}$ codes. NGrok a tunneling technology was integrated in the design to achieve a tunnel from the localhost to the online payment platform as shown in Figure 1.

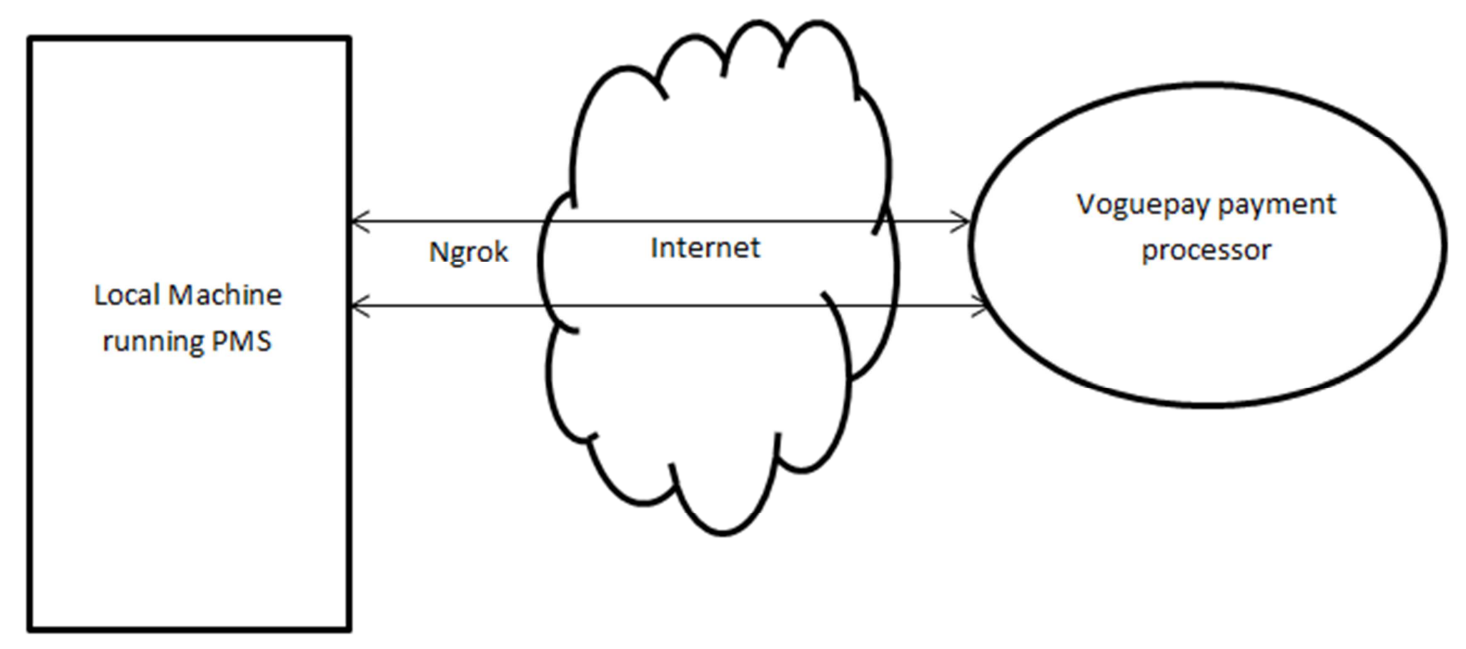

Figure 1. The Tunnel Architecture.

\subsection{Integration of the Payment Processors}

To enable integration of the Voguepay payment processor, a payment facilitating codes were developed and embedded in the ecommerce website. The codes enable the integration of the voguepay merchant ID into the ecommerce site. A voguepay account was created to generate a voguepay merchant id that uniquely identifies the voguepay account. The account was set by supplying the contact details, required application program interface (API), notification method among others. The voguepay merchant_id generated is then used for the integration. 
Figure 2. Algorithm for integrating a voguepay payment processor.

The integrated payment processor was verified using the "government issued means of identification" [12] method. The created voguepay account was funded by providing transaction details as well as selecting the payment gateway as "cash or direct transfer into voguepay bank account".

\subsection{Tunneling from Local Machine to the Internet Using Ngrok Technology}

A tunnel was created from the e-commerce website hosted locally using ngrok to access the payment platform hosted on the internet. This was achieved using the command prompt (Figure 3 to generate the public universal resource locator (url).

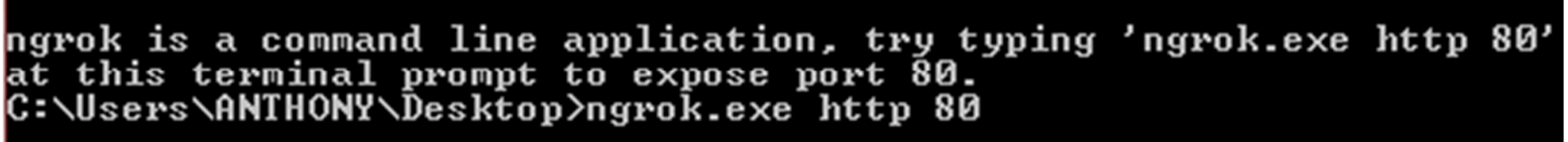

Figure 3. Ngrok tunneling through command prompt.

On the localhost where the ecommerce site was hosted, the ngrok creates a tunnel by specifying the port number for example port number 80 . The ngrok then generates a random domain name, and then route it to port 80 on the localhost by default as shown in Figure 4.

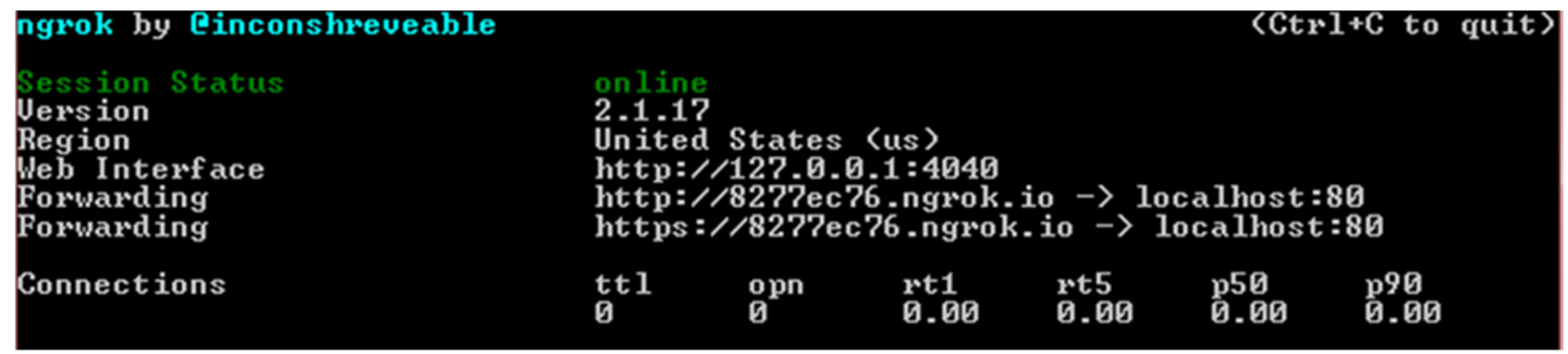

Figure 4. Screen shot showing the URL and other status information generated by ngrok.

The domain name was integrated into the success URL, fail URL and notification URL in the PHP application used in developing the e-commerce website.

\section{Results and Discussion}

The snap short in figure 5 is obtained by clicking the buy books tab in the home page of the publication marking system (PMS) developed. It shows all available products (e-books) in the book shop as well as the shopping cart used in collecting the electronic books for ordering. 


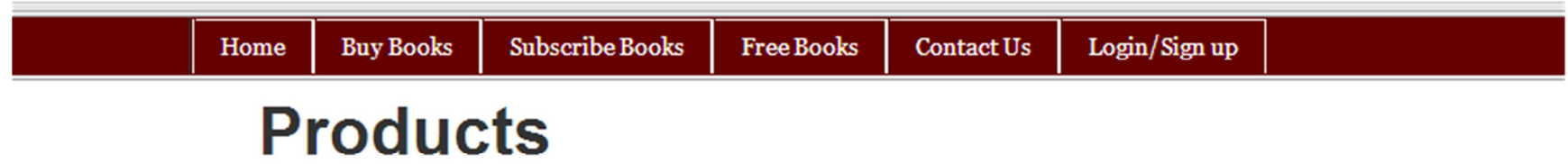

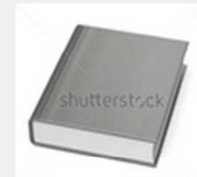

\section{Igbo History}

The Igbo history contains the analysis of Igbo society and the Igbo future

\section{Price $\$ 40.001$ Add To Cart}

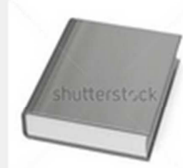

\section{Chemistry Fundamentals}

The Chemistry Fundamentals contains all basic Chemistry concepts
Your Shopping Cart

1. Igbo History

$P$ code : Lit 001

Price $: 40.00$

Empty Cart

Figure 5. E-books in PMS shopping cart ready for ordering.

$\square$ localhost/ecom/test2.php

\section{Home}

\section{Pay For Your Books With Your Card and Use the Transaction ID to access those}

\section{Books}

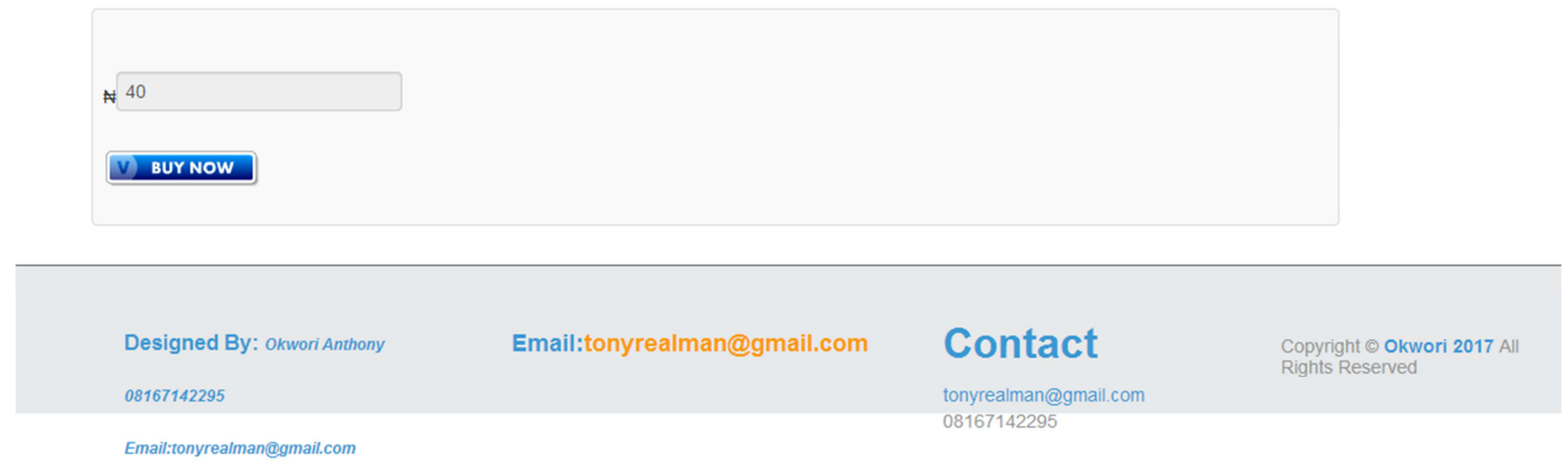

Figure 6. Order page of the PMS on local host.

The snap shot in Figure 6 is obtained by clicking the "view cart" and then "check out" buttons in the shopping cart respectively. It shows the order page of the PMS on the local machine with url: localhost/ecom/test2.php.

\subsection{Local Transaction}

When a customer placed an order by clicking the "buy now" on the ecommerce website, a secured tunnel was automatically created to the pay page of the Voguepay payment processor. The voguepay secured payment processor was loaded and prompted the customer to supply a valid email address for receiving receipt of the transaction and card particulars such as: card number, CVV2 (CVC2 $)_{1}$, Name on
Card, and card expiration date for card authentication and subsequent real time online payment.

\subsection{Payment Processing}

Ngrok technology was used by the website on the local machine to create a tunnel through the internet.

After the tunnel was created, the ecommerce website was accessed on the internet using the url [10] or [11]. The tunnel created also enables access to the pay page of voguepay payment platform from any remote machine on the internet for processing purchases of the electronic books as shown in Figure 7. 


\section{VoguePay}

\section{OCEANFLOW TECHNOLOGIES}

\begin{tabular}{|c|c|c|c|}
\hline Transaction ID & Items & Description & Price (NGN) \\
\hline $58 c 25864 a d 11 a$ & books & subscribe & 40 \\
\hline Memo & \multicolumn{2}{|c|}{ Paying for your books } & \\
\hline \multicolumn{3}{|l|}{ Total Order } & NGN40.00 \\
\hline
\end{tabular}

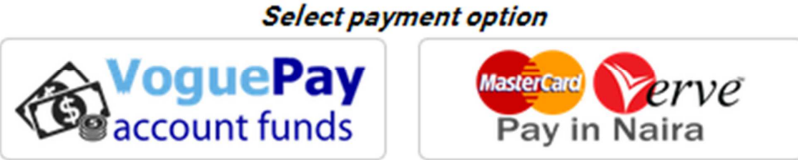

Figure 7. Pay page of voguepay payment processor.

The pay page of voguepay payment processor shows the generated transaction ID which uniquely identifies this order as well as the total cost (NGN 40.00) for the order that will be deducted from the customer's account during successful payment. It returns the customer to this merchant site after a successful or failed transaction by clicking the return to merchant site button.

\section{Conclusion}

The successful integration and verification of voguepay payment processor and tunneling of the local machine to the internet enables the local machine to establish connection from the PMS e-commerce website to the pay page of voguepay payment processor on clicking the buy now button.

This real-time online payment system for e-commerce website running on local machine demonstrates a method of integrating a voguepay payment processor for real-time online payment with an e-commerce website hosted locally. It emphasizes a secure procedure for tunneling a local machine to the World Wide Web.

\section{Acknowledgements}

This work was accomplished with the endless efforts of some friends such as Mr. John O. Okoh, David Abutu, David Ajeh, Agbo David among others. May the almighty God continue to bless you all (Amen)

\section{References}

[1] Sanjay Agal, (2011), "The design and implementation of an ecommerce site for online book sales", Chittorgarh, Mewar University.

[2] Taiwo, Tajudeen and Ebenezer, (2011), "Electronic Payment System In Nigeria: Implementation, Constraints and Solutions", Journal of Management and Society, Vol. 1, No 2, pp. 16-21.

[3] Olabisi Ajiboye, Opeyemi Kalejaiye and Olusola Dada, (2013), "Electronic Payments and Economic Growth in Nigeria", A Report by RTC Advisory Services Ltd.

[4] Okifo and Igbunu, (2015), "Electronic Payment System in Nigeria: Its Economic Benefits and Challenges", Journal of Education and Practice, Vol. 6, No. 16.

[5] Swapna kodali, (2007), "The design and implementation of an e-commerce site for online book sales", University graduate school, Indiana university south bend.

[6] NewsOfNigeria@NewsOfNigeria, (Dec 07, 2016), “Top Ten Online Payment Platforms in Nigeria", http://newsofnigeria.com/top-ten-online-payment-platformsin-nigeria/, accessed on $23^{\text {rd }}$ March, 2017.

[7] online payment gateways in Nigeria, https://www.slideshare.net/OlatunjiAdetunji1/online-paymentgateway-in-nigeria, access on $23^{\text {rd }}$ March, 2017.

[8] Alan Shreve, "ngrok tunnels: better, faster, stronger", https://inconshreveable.com/09-25-2013/ngrok-tunnels-betterfaster-stronger/ accessed on 13/03/2017. 
[9] http://blog.voguepay.com/facts-about-business-accountverification/ accessed on $4^{\text {th }}$ March, 2017.

[10] https://8277ec76.ngrok.com/ecom/index.php

[11] http://8277ec76.ngrok.com/ecom/index.php

[12] Sidhartha Reddy Vatrapu, (2014), "Design and implementation of e-commerce site for online shopping", Governors state University, University Park, Il 60484.

[13] Yang, (2009), "On-line payment and security of e-commerce", School of Kexin, Hebei University of Engineering, Handan,
China, Proceedings of the 2009 international symposium on web information systems and applications (wisa'09), Nanchang, p. r. china.

[14] http://www.tutorialspoint.com/e_commerce/e_commerce pay ment_systems.htm downloaded on $10^{\text {th }}$ December, 2015.

[15] https://voguepay.com/developers downloaded on $20^{\text {th }}$ January, 2016.

[16] https://ngrok.com/docs downloaded on 6th March, 2017.

[17] https://voguepay.com/business-info accessed on 13th/03/2017. 